
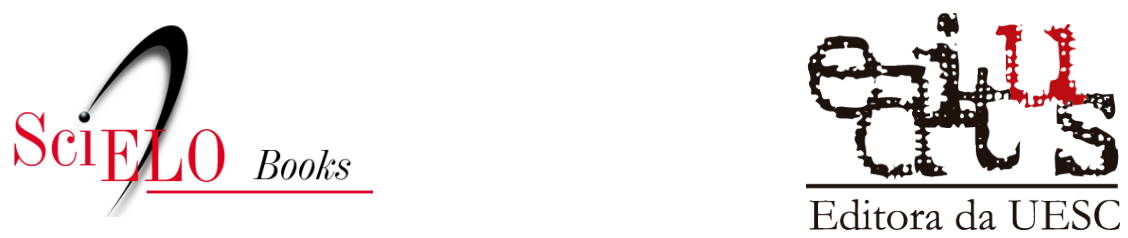

\title{
2 Narrativas histórico-acadêmicas da África e a negação de sua importância
}

\author{
Ademar Cirne
}

\section{SciELO Books / SciELO Livros / SciELO Libros}

CIRNE, A. Narrativas histórico-acadêmicas da África e a negação de sua importância. In: Racismo religioso em escolas da Bahia: autoafirmação e inclusão de crianças e jovens de terreiro [online]. Ilhéus, BA: Editus, 2020, pp. 33-47. Transfluência series. ISBN: 978-65-86213-16-4. https://doi.org/10.7476/9786586213294.0003.

\section{(c) $\underset{\mathrm{EY}}{(1)}$}

All the contents of this work, except where otherwise noted, is licensed under a Creative Commons Attribution 4.0 International license.

Todo o conteúdo deste trabalho, exceto quando houver ressalva, é publicado sob a licença Creative Commons Atribição 4.0.

Todo el contenido de esta obra, excepto donde se indique lo contrario, está bajo licencia de la licencia Creative Commons Reconocimento 4.0. 


\section{Narrativas histórico- acadêmicas da África e a negação de sua importância}

Os africanos passaram pelo processo de escravização imposto pelos colonizadores europeus que, de forma violenta, retiraram os negros do continente africano, romperam seus laços familiares, submeteram estes a péssimas condições de vida durante a viagem nos navios negreiros, além de terem os escravizado, durante quase 400 anos. Diante de toda essa vida angustiante, viam-se impelidos a agirem de forma violenta, em busca de sua libertação, a exemplo da Revolta dos Búzios (Conjuração Baiana), em 1789, e Revolta dos Malês, em 1835, das construções de quilombos, ou das ações, também violentas, dentro dos engenhos contra os seus senhores, feitores e capitães do mato.

Apesar de tudo isso, o povo escravizado resistiu e reconstruiu sua identidade cultural e religiosa, utilizando os espaços sagrados (terreiros de Candomblé), nos quais as mais velhas senhoras reuniam os mais novos para refazer os 
laços familiares, reconstruindo as bases sociais dos grupos africanos.

A história do povo de santo construida no Brasil está diretamente associada às Mães de Santos ou Sacerdotisas, principalmente no que refere à sustentação moral e espiritual das famílias de Terreiro, condição ainda presente no Brasil até os dias de hoje. Outrora, quando da escravidão, negras e negros, que ao serem comercializadas(os) e enviadas(os) para os mais diversos destinos, vendo, assim, destruídos os seus núcleos familiares consanguíneos, bem souberam restituir laços afetivos a partir dos Terreiros de Candomblé, sobretudo pela força afetiva exercida pelas mulheres.

Havia também práticas de resistência mais estratégicas, como a prática de abortos, para que seus filhos não nascessem e viessem a ser mais um instrumento de acumulação primitiva do capital dos senhores, por meio do trabaIho escravo, vítimas do processo de diáspora africana que chegou a trazer para o Brasil, via tráfico negreiro, mais de quatro milhões de negros que, escravizados, eram utilizados em vários tipos de funções, desde trabalhar na lavoura, nos serviços domésticos e até de ganho, tendo uma carga absurda e desumana de trabalho.

Ainda nos dias de hoje, em que pese não mais ser vivenciada a escravidão, homens e mulheres negras restituem seus afetos, as suas dignidades e os seus sentimentos de pertencimento no seio dos terreiros, atualmente, verdadeiros quilombos urbanos contemporâneos, espaços em que os mais velhos, especialmente a figura feminina, nas 
diversas funções em que atuam, transmitem hábitos, valores e, sobretudo, a identidade ancestral.

A seguir, uma ilustração de mulheres do Terreiro llê Axé de Ogum, no município de São Francisco do Conde, Bahia (Figura 1).

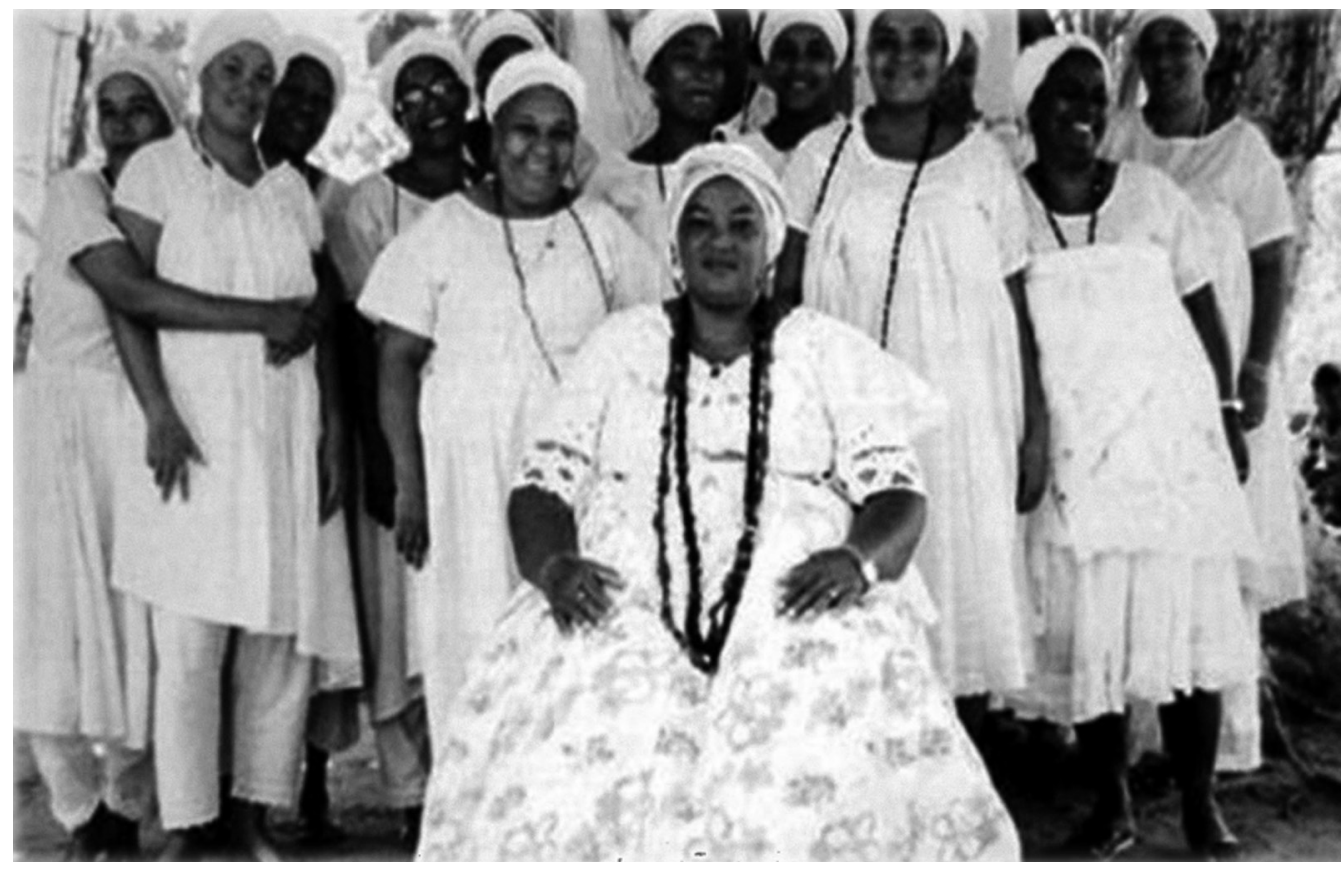

Fonte: Mulheres de Axé (REZENDE, 2013).

Figura 1

Família llê Axé de Ogum. São Francisco do Conde-Ba, 2013 
Conforme relatado acima, por meio do tráfico de escravos, a África, continente onde surgiu a humanidade e a civilização, de acordo com diversos sociólogos e/ou historiadores é inegavelmente significativa na formação do povo brasileiro, mas, apesar disso, tem uma história constantemente negada no espaço formal de educação vigente no Brasil, baseada no pensamento eurocêntrico. A essa história foram imputados, até mesmo, elementos que não fazem parte originalmente de sua cosmologia, como a figura do diabo. O próprio nome é fruto de relações exógenas e sua etimologia é de difícil caracterização (KI-ZERB, 1972 apud SILVÉRIO, 2013).

A tradição familiar africana é um dos instrumentos de compreensão das articulações de pequenas e/ou grandes redes de sociabilidade entre grupos étnicos com algum tipo de afinidade, que geravam riscos e benefícios na "disputa pelo acesso aos rios, pelo controle sobre estradas ou rotas e pela construção de impérios e reinos importantes, tais como Império Egípcio e Mali, Reino Kongo, Povo Banto, Iorubá, Sudanês e Moçambique" (ALBUQUERQUE; FRAGA FILHO, 2006, p. 14). Os conflitos entre eles fizeram surgir uma escravidão doméstica no continente africano, influenciada por vínculos de parentesco, o que possibilitava a assimilação completa de indivíduos e grupos de escravos.

Essa concepção tradicional, de ampliação dos limites demarcadores dos vínculos parentais na construção de amplas unidades familiares permanece viva em território brasileiro, ainda que reinventada a partir da fusão com outras tradições, sobretudo as indígenas (ALBUQUERQUE; FRAGA FILHO, 2006, p.15). 
As navegações europeias e as trocas comerciais estabelecidas com os africanos no século XVI deram origem ao sistema colonial-escravista brasileiro, o qual se fundamentou no trabalho forçado de cerca de 15 milhões de homens e mulheres "arrancados de suas terras" (REIS; GOMES, 1996). Durante mais de três séculos, a relação entre tráfico de africanos, captura de indígenas no interior e utilização de mão de obra escravizada nas atividades laborais foi fundamental para o desenvolvimento da economia portuguesa, como descrevem Albuquerque e Fraga Filho.

\begin{abstract}
A retirada violenta de africanos de suas comunidades, conduzidos para trabalhar como escravos em terras distantes, foi a solução encontrada pelas potências coloniais europeias para povoar e explorar as riquezas tropicais e minerais das colônias no Novo Mundo. A colônia portuguesa (o Brasil) dependia de grande suprimento de africanos para atender às necessidades crescentes de uma economia carente de mão-de-obra. A migração transatlântica forçada foi a principal fonte de renovação da população cativa no Brasil, especialmente nas áreas ligadas à agricultura de exportação, como cana-de-açúcar. Submetida a péssimas condições de vida e maus-tratos, a população escrava não se reproduzia na mesma proporção da população livre. Era alto o índice de mortalidade infantil e baixíssima a expectativa de vida.
\end{abstract}

O tráfico negreiro realizado pelos países da Europa durante o período do Antigo Regime foi uma das mais importantes formas de acumulação de capitais da burguesia comercial, construindo as condições para consolidação do sistema capitalista após a eclosão da revolução industrial no século XVIII (SILVA, 2012). 
Ocorre que, apesar de tamanha desumanidade durante os séculos de cativeiro, a população africana e afro-brasileira conseguiu manter um intenso processo de resistência, em vários âmbitos e, conforme Schwartz (2001, p. 219-220),

A recalcitrância cotidiana, a lentidão no ritmo de trabalho e a sabotagem eram, provavelmente, as formas mais comuns de resistência, ao passo que a autodestruição por meio de suicídio, infanticídio ou de tentativas manifestas de vingança eram as mais extremas no sentido pessoal. No Brasil, os exemplos mais drásticos de atos coletivos foram as inúmeras rebeliões de escravos ocorridas no início do século XIX na Bahia, porém rebeliões como a dos malês, em 1835, foram episódios verdadeiramente extraordinários. A forma mais comum de resistência escrava no Brasil colonial era a fuga e um dos problemas característicos do regime escravista brasileiro era a existência contínua e generalizada de comunidades de fugitivos, que recebiam diversas denominações: mocambos, ladeiras, magotes ou quilombos.

Prova disso é que, mesmo com péssimas condições de vida e alto índice de mortalidade infantil, as formas de resistências construídas pelas negras e negros garantiram a perpetuação do grupo social, permitindo que a população brasileira, na época da independência, fosse composta, de acordo com Viotti da Costa (1998, p. 19), por

[...] aproximadamente um milhão e 347 mil brancos e 3 milhões e 993 mil negros e mestiços entre escravos e livres. Em certas áreas, os cativos constituíam maioria absoluta. Sua distribuição era irregular, em alguns pontos mais concentrada, como Pernambuco, Bahia, Minas Gerais e Rio de Janeiro. Os caminhos da escravidão seguiam as etapas da economia. 
Percebe-se que a população negra no Brasil está concentrada nas regiões onde ocorreu a maior concentração de atividade econômica para exportação, já que quase toda mão de obra utilizada nesse processo produtivo e extrativista era composta pelos escravos negros.

Vê-se, portanto, que não se pode conceber a escravidão sem a forte presença de uma resistência que perpassou todos os aspectos da vida social e cultural dos cativos. Entretanto, consoante Reis e Gomes (1996), isso não significa que todo o processo de resistência teve como princípio a criação de uma sociedade alternativa livre.

A especialização das forças repressivas contra a resistência da população negra, inclusive as culturais, tem influência também no surgimento das Religiões de Matriz Africana no Brasil, em meio à proibição religiosa que se estabeleceu por conta da predominância das religiões de Matriz Judaico-cristã na colônia. Estas proibiam qualquer tipo de manifestação religiosa dos negros livres ou escravizados, o que fez surgir entre esta população a perspectiva do sincretismo religioso que, dentro das senzalas, era usado para continuar reverenciando os deuses africanos (Orixás), sem que os senhores brancos percebessem o verdadeiro sentido da manifestação, como se pode verificar por meio do entendimento de Bastide (1971 apud SOARES, 2002 p. 45-75):

O assim chamado sincretismo resulta de três modalidades de relação: estrutural, cultural e sociológica. O africano leva o panteão católico, transbordante de santos e virgens-marias, a partir da relação entre os orixás intercessores e Olorum, deixando de lado, no entanto, a ideologia católica do "sofres aqui para gozar além". 
Portanto, ao menos no início, será a religião africana a purificar o catolicismo quando aceita o culto ao santo.

A vivência frequente do autor nas Casas de Religião de Matriz Africana nos últimos anos permitiu perceber, cada vez mais, como a ideia do sincretismo religioso foi uma estratégia da população negra para a manutenção dos seus princípios religiosos trazidos da África. Atualmente, as relações entre os orixás africanos e os santos da igreja católica podem até continuar existindo dentro dos terreiros, porém com uma distinção do que seja o orixá e o santo católico, dessa forma, já não é mais preciso esconder o orixá por trás de um santo.

É nesse contexto de resistência que as religiões de matriz africana aparecem como um dos principais elementos de socialização e educação para as crianças e jovens negros, que durante praticamente toda existência são tratados com indiferença e discriminação no seu cotidiano e, principalmente, no ambiente escolar, o que se constitui em racismo religioso.

Diversas pesquisas acadêmicas têm se dedicado ao estudo das relações existentes entre as religiões de matriz africana e a educação. Dentre estas, destacam-se as obras da professora Caputo (2012), que trata da relação que a escola formal estabelece com as crianças de terreiro. Em sua tese de doutorado, a autora relata o resultado de uma pesquisa feita durante cerca de 20 anos no Terreiro de Mãe Palmira, na Baixada Fluminense, no Rio de Janeiro, pela qual acompanhou o crescimento de, pelo menos, cinco crianças dos 4 aos 20 anos e suas relações com o ambiente escolar. Em outra obra, esta mesma autora trata de como se 
estabelece a relação do Candomblé com a educação formal, a partir de uma análise multiculturalista crítica (CAPUTO, 2013).

Dois livros da professora Eliane Cavalleiro, Do silêncio do lar ao silêncio escolar: racismo, preconceito e discriminação na educação infantil (CAVALLEIRO, 2000) e Racismo e antirracismos na educação: repensando a nossa escola (CAVALLEIRO, 2001), apresentam importantes considerações sobre a discriminação racial sofrida por crianças em sala de aula. Embora não tratem especificamente do racismo religioso, também evidenciam o problema vivenciado por esta população.

Além das já citadas, a obra As águas de Oxalá, de Beniste (2009), apresenta, de forma didática, os conceitos filosóficos fundamentais para o entendimento do Candomblé, utilizando-se, inclusive, no texto, da linguagem Yorubá ${ }^{5}$ acompanhada de tradução, o que permite uma melhor compreensão do significado dessa prática religiosa. O trabalho do Professor Carneiro (2002) é de fundamental importância para compreensão do imenso processo de perseguição que os terreiros e seus frequentadores sofreram na Bahia durante a segunda metade do século XX, e das formas de organização e resistência dessas comunidades.

Em todo um contexto histórico de desvalorização e desrespeito às pessoas negras e suas manifestações religiosas, a despeito da valiosa contribuição desta raça para a formação brasileira e, contrastando com as alterações jurídicas que buscavam reverter este ultraje, verificadas no decorrer do tempo, a escola e a sociedade necessitam conhecer a respeito do racismo religioso, que persiste na 
sociedade brasileira; além disso, deve se engajar para superá-lo efetivamente.

A trajetória deste autor no movimento negro, assim como nos terreiros de Candomblé e na academia, o fez perceber uma necessidade de mudança no conceito original utilizado para definir o que acontecia com as crianças e jovens de terreiros no ambiente escolar. A princípio, chamava a discriminação a qual eles passavam de intolerância religiosa, acreditando se tratar apenas de uma reação às práticas e rituais que estes realizavam em seus espaços religiosos.

A maior convivência, tanto na academia como nos movimentos sociais e religiosos, assim como os contatos cada vez mais frequentes com as crianças e jovens nos terreiros, foi demonstrando que a questão era bem mais ampla e que a reação a estas crianças e jovens ia muito além da intolerância, na verdade, as ações contra estes grupos eram realizadas acompanhadas de muito ódio e raiva, associando estas pessoas sempre com concepções diabólicas e negativas.

Essas ações, na maioria das vezes praticadas contra as crianças negras, apresentam-se como uma prática racista, pois, não se trata apenas de tolerar ou não as práticas religiosas, mas sim de desqualificar, humilhar e segregar, provocando a separação radical entre brancos (católicos e ou evangélicos) e "negros macumbeiros, demoníacos". A leitura do trabalho de Araújo (2015) torna-se bem esclarecedora no que diz respeito a essa questão, o que se verifica na citação a seguir. 
Parto da hipótese de que as diferentes formas de intolerância religiosa infligidas contra pessoas ligadas às religiões afro-brasileiras no ambiente escolar (professores, alunos, gestores, funcionários, etc.) revelam uma forma de racismo. Tenho que admitir, porém, que a associação entre racismo e intolerância religiosa nem sempre foi admitida e dificilmente se mostrou evidente. E na maioria das vezes em que se percebeu essa correlação a discussão foi feita, majoritariamente no âmbito da academia. Todavia, essa discussão não pode se limitar à esterilidade das discussões meramente acadêmicas. Isso tem que mudar. É possível mesmo falar de algumas mudanças, que, contudo, ainda são tímidas, mas essa realidade começa a mudar. A mudança é lenta. Porém, já começa a se tornar perceptível. Um dos sinais dessa mudança está representado no fato de já se perceber uma compreensão e admissão da associação que há entre intolerância religiosa e o racismo, mudança que de início pode parecer muito elementar, contudo, carrega um simbolismo muito grande para as vítimas desse tipo de violência (ARAÚJO, 2015, p. 48)

As Figuras 2 e 3, a seguir, demonstram que o conceito de racismo religioso já vem sendo tratado de forma ampla, não só pela academia, mas também em eventos que mobilizam a sociedade no sentido de explicitá-lo e combatê-lo.

Essas imagens retratam como a sociedade civil organizada vem se mobilizando e promovendo uma série de atividades públicas, por meio das quais se expressa a indignação dos religiosos de matriz africana em relação às práticas de racismo religioso contra eles, e a citação de Nascimento (2017, p. 53) deixa claro a importância de entender todos estes ataques como práticas de racismo:

É fundamental ressaltar o entrecruzamento das relações entre racismo e práticas de violência, relacionado aos ataques às "religiões de matrizes africanas". E isto não é um detalhe, pois como 
lembra Lélia González (1983), o racismo é uma espécie de “neurose cultural", que se beneficia ao esconder seus sintomas, para - não aparecendo - fingir que não existe e, com isso, dificultando em muito o seu enfrentamento. Por isso, combater as práticas violentas contra as "religiões" de matrizes africanas é, também e sobretudo, combater a herança colonial do racismo que, embora tenha muitas maneiras de expressar-se, segue mascarada em nosso país.

Pode-se também observar na citação que boa parte das vezes que as casas de matriz africana são atacadas e resolvem prestar queixa nas circunscrições policiais as autoridades tentam desconsiderar o fato como crime de racismo e enquadrar como "briga de vizinhos", na tentativa de esconder o racismo do nossos país.

De acordo com o professor Wanderson Flor do Nascimento (2017), da UNB, historicamente falando, a primeira vez que a expressão racismo religioso apareceu no contexto acadêmico foi no trabalho de conclusão de curso de Lima (2012), por meio do qual ela afirma que

\footnotetext{
[...] o racismo pode ser definido como crenças na existência de raças superiores e inferiores. Dessa forma é passada a ideia de que por questões de pele e outros traços físicos, um grupo humano é considerado superior ao outro. Ao direcionar os argumentos racistas para as religiões, tem- se o racismo religioso, através do qual se discrimina uma religião. (LIMA, 2012 apud NASClMENTO, 2017, p. 55).
}

No contexto do movimento social, o conceito de racismo religioso aparece antes do acadêmico. Conforme apontam os estudos de Nascimento (2017), um dos primeiros estudiosos do tema, esta expressão aparece em 2009 , 
quando a Secretaria de Política de Promoção da Igualdade Racial - SEPPIR realiza uma reunião para discutir políticas públicas para povos e comunidades tradicionais. No seu artigo, Nascimento (2017, p. 55) afirma:

Mas a história do uso do conceito não começa aí. No ano de 2009 , Nilo Nogueira, então Assessor Técnico da Secretaria de Políticas para Comunidades Tradicionais da Secretaria Especial de Políticas de Promoção da Igualdade Racial, convocara uma reunião com lideranças dos povos de terreiro de vários lugares do Brasil para a discussão daquilo que deveria ter sido o Plano Nacional de Proteção da Liberdade Religiosa. Nilo Nogueira tem um longo histórico de comprometimento com os povos de terreiro e com o enfrentamento ao racismo. Na ocasião, duas das mais destacadas lideranças - Beatriz Moreira Costa, conhecida como Mãe Beata de Yemanjá e Valdina Pinto, conhecida como Makota Valdina apresentavam uma ideia com a qual elas já estavam trabalhando a algum tempo em seu ativismo. Elas diziam "Não queremos ser toleradas! Queremos ser respeitadas!". Nesse momento, a ideia de intolerância religiosa e seu enfrentamento pela promoção da tolerância se mostrava insuficiente ou inadequada para a perspectiva advogada por elas. É nesse momento, que a ideia já percebida por muitas pessoas que militavam contra o preconceito que atinge as comunidades de terreiro toma nome: quando elas afirmam que querem ser respeitadas, eu me pergunto o que motivaria tal desrespeito, e foi aí que apareceu a expressão: racismo, racismo religioso.

Precisa-se, no entanto, aprofundar os estudos e discussões sobre o conceito de racismo religioso para construir formas de combate a essa violência contra as comunidades religiosas de matriz africana, principalmente para desfazer a ideia que os racistas religiosos transmitem, a qual reduz estas instituições a espaços onde se praticam apenas rituais 
religiosos, não compreendendo ou rejeitando toda complexidade da vida social e da herança cultural dos povos africanos trazida para o Brasil e mantida viva nas casas religiosas de matriz africana. Essa visão limitada da problemática direciona para uma disputa meramente no campo religioso entre grupos de religiões diferentes, criando uma ideia falsa que esconde as práticas racistas, ocultadas na ideia de tolerância ou intolerância religiosa.

O capítulo 3, a seguir, trata da trajetória do movimento negro no Brasil e de sua relação com o combate ao racismo religioso, apontando o multiculturalismo crítico como possível caminho de uma educação antirracista. 